\title{
An analytic hierarchy process for benchmarking of automobile car service industry in Indian context
}

\author{
Bhupender Singh $^{\mathrm{a}^{*}}$, Sandeep Grover ${ }^{\mathrm{b}}$, Vikram Singh ${ }^{\mathrm{c}}$ and Rajesh Attri ${ }^{\mathrm{d}}$
}

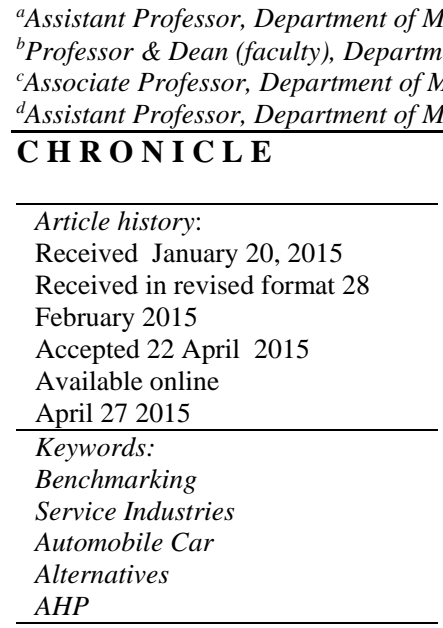

\section{Introduction}

The quintessence of benchmarking is the process to identify the highest values of superiority for services or products and then create the environment for improvements to reach individuals standards is called as best practices, which requires continuous improvement for quality (Dattakumar \& Jagadeesh 2003). It is very useful tool for improving the weakness through development processes where industry measures its concert against group leader (Saunders \& Smith, 2007). Benchmarking is mostly adopted by industries to recognize how glowing they are performing in market relative to their competitors. It can be used to identify what type of management practices is advisable to apply in individual firm to achieve desired concert goals. In order to compete today's environment, many organizations have recognized benchmarking as strategic important for improved performance and commitment to achieve competitive advantage (Gleich et al., 2008). There are many studies that investigated the method about performance evaluation (Singh \& Grover 2015a; 2015b; Gleich et al.,

\footnotetext{
* Corresponding author. Tel: +09416702828

E-mail address: bhupee_28@yahoo.co.in (B. Singh) 
2008; Wynn-Williams, 2005). It is essential for the application of performance measurement that a company's tangible and intangible targets are defined in a way that is more appropriate to the requirements. These are many studies to identify different key performance indicators, including tangible and intangible aspects (Himes, 2007; Jones \& Kaluarachchi, 2008; Mukherjee, Nath \& Pal, 2002; Robson \& Prabhu, 2001; Wainwright et al., 2005). Wong and Wong (2008) defined benchmarking as a management tool that is used for searching of systematic process for best practices and new ideas to continuous improvement. It is defined as a continuous analysis of strategies, functions, processes, products or services, performances, etc. compared within or between best-in-class organizations by obtaining information through appropriate data collection methods, with the intention of assessing an organization's current standards and thereby carry out self-improvement by implementing changes to scale or exceeding those standards (Anand \& Kodali, 2008). Many companies including but not limited to Hi-Tech product manufacturing, automotive, paint, apparel and SMEs have applied a benchmarking approach successfully in different areas to enhance performance across various dimensions (Deros et al., 2006; Wong \& Wong, 2008). Parmar et al. (2010) presented a clustering algorithm, named min-min-roughness to cluster suppliers into smaller, more manageable groups with similar characteristics. Multiple criteria decision-making (MCDM) has become swiftly a major part of research for dealing with multifaceted decision problems where globalization has put industries into fierce competition and customers are enjoying quality of products with better services in lesser prices. Traditional manufacturing and service methods are not sufficient for survival in this ever closing competition so there is a need for industries to adopt new methods and techniques to improve the effectiveness of their systems such as TQM, JIT, advanced manufacturing and many more for achieving Benchmarks. These newer technologies although provide great deal of advantages at every operation, yet industries have failed to yield the anticipated benefits completely due to complex nature of these technologies, which depend on many critical success factors. So there is a need for understanding obligation of services towards customers, which gives a benchmark model for the industries to maintain their existence as a market leader. Many global manufacturing companies such as Sony, Honda, Maruti, Ford, General Motors, General Electric, Nissan, Toyota, John Deere, HP,Wal-Mart, National Grid Company (UK), Dell, Whirlpool, and Pontiac have adopted the approaches in order to enhance the internal capability of the industries and improve the overall performance of system (Hartley \& Jones,1997; Dunn \& Young, 2004;).

\section{Literature review}

\subsection{Benchmarking}

Many researchers have conducted the ample literature survey on benchmarking (Yasin, 2002; Dattakumar \& Jagadeesh, 2003; Singh \& Grover, 2015a). According to Smith (2000), service sector can also be beneficial using consumer benchmarking to increase competitiveness. It should be expanded to service industry as customer-oriented is increasingly concerned nowadays. For example, international roaming service have applied benchmarking to improve the performance in the particular service industry (Chin et al., 2001). Landeghem and Persoons (2001) used causal model to benchmark the logistical operations which composed of four main logistics objectives and relates the use of best practices to the resulting performance regarding the objectives. Benchmarking practice was first applied by some companies in the 1970s using benchmarking tools to compare key production parameters and verify whether could improve processes enhanced company performance. Studies of best practices with regard to operational results, employees' capabilities, innovative performance, and even services outcomes tend to become technical, focusing on quantifiable evidence (Menor \& Roth, 2007). Dattakumar and Jagadeesh (2003) suggested that firms move their focus of benchmarking for more useful and a versatile tool in the quality tool box. Many researchers have conducted a comprehensive literature survey on benchmarking (e.g. Jackson et al., 1994; Zairi \& Youssef, 1995; Yasin, 2002; Dattakumar \& Jagadeesh, 2003). Many benchmarking processes in e-commerce have been reported, for instance Ahmed et al. (2006) demonstrated global benchmarking for internet and ecommerce applications and Rickards (2007) evaluated the benchmarking's for the development for a 
small and medium enterprise. As the requirements of benchmarking become more dynamic, the research methods have come to contain case studies (Yam et al., 2000; Rajagopal et al., 2009), empirical studies (Simatupang \& Sridharan, 2004; Magd, 2008), conceptual framework studies (Kourteli, 2000; Leung \& Lee, 2004; Wait \& Nolte, 2005) and mathematical and statistical modeling (Brandmeier \& Rupp, 2010; Mehregan et al., 2010; Sreekumar \& Mahapatra, 2011). The competitiveness of organization is translated into organizational financial performance and market position and overall competitive advantage (Dawkins et al., 2007; Ojeda-Gomez et al., 2007). Such performance measures involve small and medium enterprises (Cassell et al., 2001; Hwang \& Lockwood, 2006; Gomes et al., 2009), traditional manufacturing firms (Meybodi, 2009), large geographical areas (Monge et al., 2006), and supply chain entities (Chia et al., 2009). Service is the main factor of benchmarking (Koller \& Salzberger, 2009; Wong \& Wong, 2008) apply service tools in benchmarking process and strategybased benchmarking for large organizations (McAdam et al., 2008; Choy et al., 2007; Dawkins et al., 2007; Moffett et al., 2008). The requirement of benchmarking as a tool in service sector is very important (Boonitt \& Pongpanarat, 2011; Hallgren \& Olhager, 2009; Narasimhan et al., 2006; Baltacioglu et al., 2007).

\subsection{Benchmarking using MCDM}

Although some researchers used benchmarking as a tool to improve the quality of product or service, only a few could work with a particular service industry. Most often, they discussed the methodology of benchmarking using various MCDM approaches such as AHP, ANP, TOPSIS, Graph Theory and many more. Apart from this, many researchers have also utilized various techniques in benchmarking for instance AHP has been successfully utilized for benchmarking in process performance (Frei \& Harker, 1999), strategic performance (Partovi, 2001), quality performance (Min \& Chung, 2002), logistics performance of the postal industry (Chan et al., 2006) and online retailing performance (Kabir \& Hasan 2012). Moreover, a measuring system is carried out to evaluate the benefits from the good practice. Lin et al., (2008) used AHP and TOPSIS approaches for customer driven product design process and found suitable results. ANP model was developed by Saaty (2005) which allows modeling the decision problem as a network of inter-related elements. Singh and Kumar (2013) explained hybrid methodology by using AHP and TOPSIS for measuring utilization of automated manufacturing technology. Kabir and Hasin (2013) showed framework for benchmarking online retailing performance using Fuzzy AHP and TOPSIS. Perçin (2009) presented an application of two phase AHP and TOPSIS for evaluation of third party logistics.

Gangurde \& Akarte (2013) studied relationship to customer preference oriented product design using AHP and modified TOPSIS approach. Since service industries have tried to develop their operational performance outcomes in every field, many benchmarking have moved in new areas of emerging market to improve effectiveness (Mitra Debnath \& Shankar, 2008). Buyukozkan et al. (2008) developed a hybrid model using fuzzy AHP and fuzzy TOPSIS for selection of suitable strategic alliance partner in logistics value chain. AHP is a problem-solving framework and flexible, systematic method employed to represent the elements of a complex problem. The general structure of AHP is shown in Fig. 2. The characteristics of AHP allow both qualitative and quantitative attributes to be used for selection process such as bank selection decision (Ta \& Har, 2000). The dimensions of study is carried out by literature and shown in Table 1.

The AHP-based approach is explained to identify and prioritize logistics critical success factors (CSF) to evaluate the performance levels. Consequently, competitive advantage and disadvantage can be highlighted for continuous improvement. Although, AHP allows both qualitative and quantitative attributes to be included with the measurement of qualitative attributes that may be different for various industries like manufacturing, services etc. where consistent judgment is required. 
Table 1

Dimensions for Service

\begin{tabular}{|c|c|c|}
\hline Dimensions & Criterion & Definitions \\
\hline \multirow[t]{2}{*}{ Tangibles } & Building layout & Aesthetic, being convenient of the Industry \\
\hline & Equipment & $\begin{array}{l}\text { The availability of machinery in the production system achieving to } \\
\text { Rate }\end{array}$ \\
\hline \multirow[t]{3}{*}{ Responsiveness } & Timeliness & $\begin{array}{l}\text { Ability to provide operations and promised production \& quality on } \\
\text { time }\end{array}$ \\
\hline & Completeness & The availability of all kind of services perfectness at time \\
\hline & Willingness & Helping employees willingly \& completing requirements \\
\hline \multirow[t]{4}{*}{ Reliability } & Accuracy & $\begin{array}{l}\text { Accuracy, consistency given information regarding dimensions, } \\
\text { production rate, etc. }\end{array}$ \\
\hline & Expertise & Authority of staff providing reliability to specialized \\
\hline & Image & Creating good vision to staff and maintain it \\
\hline & Security & Protection of every type of system data \\
\hline \multirow[t]{3}{*}{ Assurance } & Salary/rewards & Favorable payment at time \& regard with money \\
\hline & Courtesy & Courtesy of personnel and their ability to inspire trust and confidence \\
\hline & Compensation & To give guaranty to the employees in case of a problem \\
\hline \multirow[t]{3}{*}{ Empathy } & Caring & Individualized service attention \& understanding needs of employees \\
\hline & Manner & The attitude of personnel in the department setting \\
\hline & Communication & $\begin{array}{l}\text { Transfer of information between personnel and employees, the degree } \\
\text { of interaction level of two-way communication }\end{array}$ \\
\hline \multirow[t]{3}{*}{ Professionalism } & Skill & Competence and performance of staff \\
\hline & Experience & The accumulation comes into existence step by step \\
\hline & Innovation & $\begin{array}{l}\text { Developing the personnel and hospital services, by trainings, using } \\
\text { new technologies }\end{array}$ \\
\hline
\end{tabular}

AHP methodology is employed for sustaining the entire benchmarking process where it can facilitate the complex measurement system into hierarchy of criteria to give a clear view on performance levels with respect to each individual criterion for the car service industries. Selection of attributes and alternatives can be accomplished by AHP so that each criterion could be considered one by one to find out the optimal solution from literature. This paper aims to provide a complete framework for benchmarking performance of Automobile Car Industry in India, so that CSFs could be identified. Based on these CSFs, their performance can be measured and evaluated against the best-in-class company to find out their competitive advantages and disadvantages. Learning from the leading company, they can select the best practice that is most suitable for their improvement. The focus is to ensure a comprehensive study of how the performance of car service is benchmarked using a consistent measuring system. Critical success factors and alternatives are identified from literature and further prioritized by using AHP where their relative importance has also been found.

As shown in Table 1, various dimensions are located from literature, those will be taken as Attributes for Tangibles, Responsiveness, Reliability, Assurance, Empathy, Professionalism and alternatives will be find out by AHP approach. In fact, benchmarking can be used as a quality improvement tool to increase the competitiveness for the Automobile Industry. It can be enabled car service provider to find out their current position among competitors with the measurement gaps. A questionnaire survey are made among different type of customers (120 Customers per company) to 50 different car service provider. Out of 50 only 20 filled their questionnaire completely including their own feedback policy. So the authors found reasonable response rate for analyzing the data obtained and convert the data into different score as instrument. Further these scores will be used as per figure no.4for finding best performer in the market. 


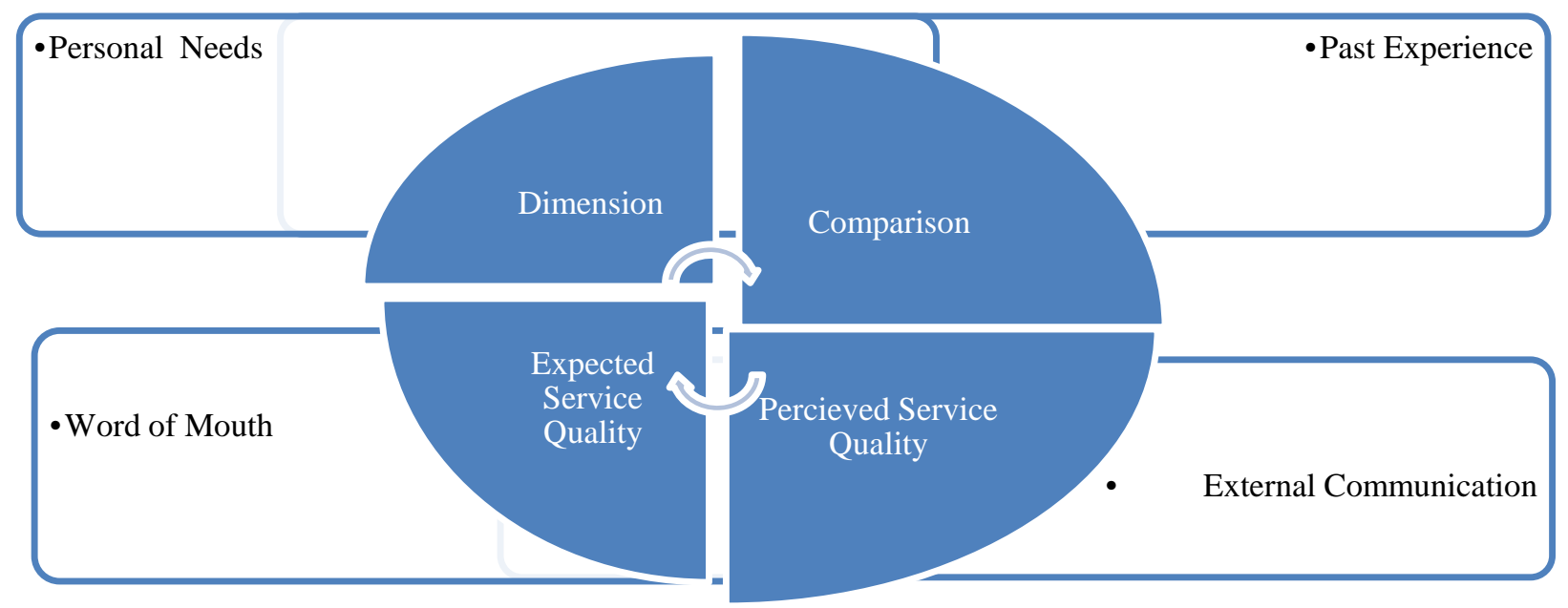

Fig. 1. Customer Assessment for service quality

\section{Development of AHP methodology for Benchmarking}

The criteria and sub-criteria include in the split phases of AHP are specific to Car service. A specified measurement system is derived to make the judgment of both qualitative and quantitative attributes. However, the proposed framework does not restrict the setting of the rating and evaluation standard. Users can always modify the rating and evaluation standard to suit for particular concerns. In this connection, they are subjected to changes in the preference of customer, so it should be constantly reviewed. As per literature review, the AHP approach comprises of following steps which includes

Step 1: Statement of the problem: Here, the objective is to benchmark the performance of an automobile car service industry.

Step 2: Determine the overall objective and its evaluation factors:

In this step, the overall objective and its evaluation factors are determined. For this purpose, a hierarchical structure is established with the objective at top level, evaluation factors at second level, and the alternatives at third level. The three level AHP model of the current problem is shown in Fig. 2 .

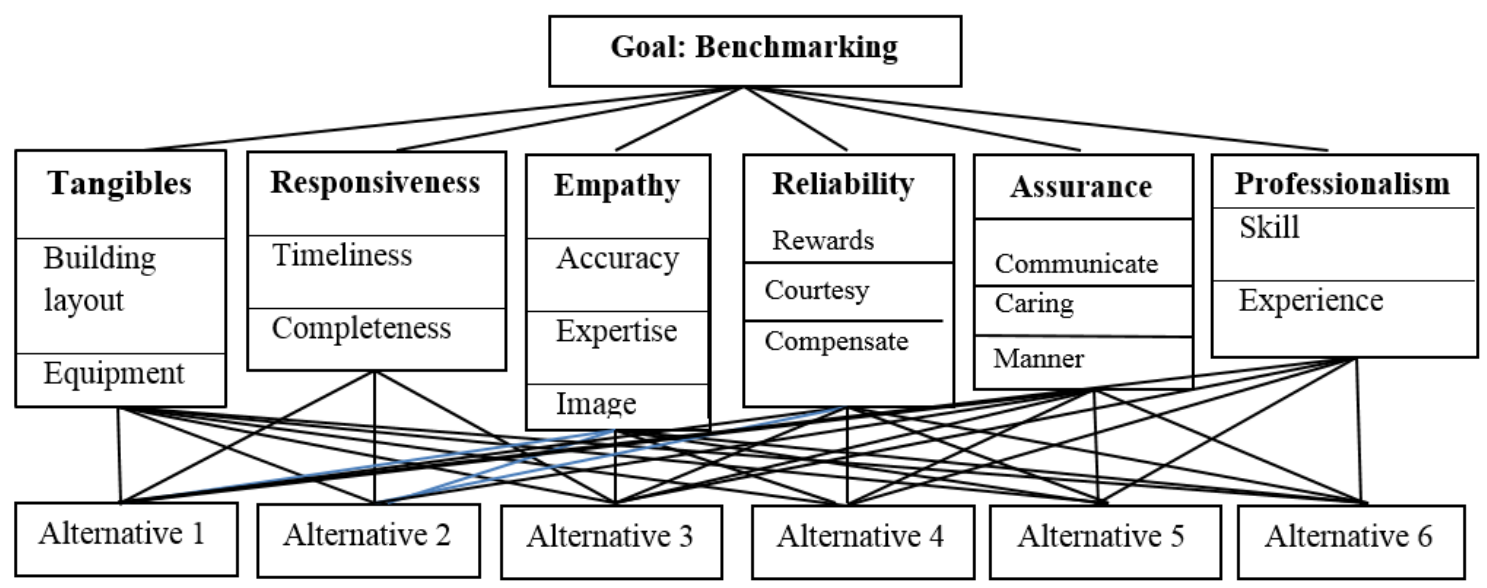

Fig. 2. General Structure of AHP

Step 3: Determination of relative importance of factors with respect to objective:

(a) Construction of pair-wise comparison matrix: In this step of AHP approach, a pair-wise comparison matrix is developed by utilizing the fundamental scale of relative importance. For this purpose, Table 2 is used. 
Table 2

Relative importance of factors

\begin{tabular}{ll}
\hline Relative importance $\left(a_{i j}\right)$ & Description \\
\hline 1 & Equal importance of $I$ and $j$ \\
3 & Moderate importance of $I$ over $j$ \\
5 & Strong importance of $I$ over $j$ \\
\hline 9 & Very strong importance of $I$ over $j$ \\
$2,4,6,8$ & Absolute importance of $I$ over $j$ \\
\hline
\end{tabular}

(b) Determination of relative normalized weight $\left(W_{i}\right)$ of each factor: Relative normalized weight of each factor is determined by

(i) Calculate the geometric mean of $i^{\text {th }}$ row.

$\mathrm{GM}_{\mathrm{i}}=\left[\prod_{j=1}^{N} a_{i j}\right]^{1 / N}$

(ii) Normalize the geometric means of rows in the comparison matrix.

$W_{j}=\frac{G M_{i}}{\left[\prod_{j=1}^{N} G M_{i}\right]}$

(iii) Calculate matrices $\boldsymbol{A}_{3}$ and $\boldsymbol{A}_{4}$ : In this step, matrix $A_{3}$ and $A_{4}$ are calculated such that $A_{3}=$ $A_{1} \times A_{2}$ and $A_{4}=\frac{\mathrm{A}_{3}}{\mathrm{~A}_{2}}$

where $A_{2}=\quad\left[W_{1}, W_{2}, W_{i}, \ldots, W_{N}\right]^{T}$

(iv) Determine the maximum eigenvalue $\left(\lambda_{\max }\right)$ : In this step, maximum eigen value is determined, which is the average of matrix $A_{4}$.

(v) Calculate the consistency index $(\boldsymbol{C I})$ : The consistency index is calculated as $\frac{\left(\lambda_{\max }-N\right)}{(N-1)}$

The smaller is the value of $C I$, the smaller is the deviation from consistency.

(vi) Obtain the random index $(\boldsymbol{R I})$ : Find the value of random index $(R I)$ by utilizing Table 3 .

Table 3

Random Index $(R I)$ values

\begin{tabular}{lllllllll}
\hline No. of factors & 3 & 4 & 5 & 6 & 7 & 8 & 9 & 10 \\
\hline RI & 0.52 & 0.89 & 1.11 & 1.25 & 1.35 & 1.4 & 1.45 & 1.49 \\
\hline
\end{tabular}

(vii) Calculate the consistency ratio: Consistency ratio $(C R)$ is calculated as $\frac{\mathrm{CI}}{\mathrm{RI}}$

Usually, a $C R$ of 0.1 or less is considered as acceptable for matrix of size $5 \times 5$ or more which replicates an unprejudiced conclusion of the experts. The pairwise comparison matrix for the current problem is shown in Table 4. 
Table 4

Final Value of AHP

\begin{tabular}{llllllll}
\hline CSFs/Alts & AS & EA & RA & PO & RP & TG & PV value \\
\hline AS & 1 & 3 & 2 & 2 & 2 & 0.3333333 & 0.209 \\
EA & 0.33 & 1 & 2 & 2 & 0.5 & 0.3333333 & 0.118 \\
RA & 0.5 & 0.5 & 1 & 2 & 0.5 & 0.3333333 & 0.099 \\
PO & 0.5 & 0.5 & 0.5 & 1 & 0.5 & 0.3333333 & 0.077 \\
RP & 0.5 & 2 & 2 & 2 & 1 & 0.5 & 0.162 \\
TG & 3 & 3 & 3 & 3 & 2 & 1 & 0.335 \\
\hline Total & 5.83 & 10 & 10.5 & 12 & 6.5 & 2.8333333 & CR=0.050 \\
\hline
\end{tabular}

where, AS= Assurance, EA= Empathy, $\mathrm{RA}=$ Reliability, $\mathrm{PO}=$ Professionalism, $\mathrm{RP}=\mathrm{Responsiveness,}$ $\mathrm{TG}=$ Tangibles are considered.

The consistency ratio of the decision maker's judgement comes to be 0.050 . This shows that results are quite consistent.

Step 4: Determine the solution to the problem: After the computations of the relative importance of factors, the next step in AHP approach is to synthesize the solution to the problem. Table 4 also shows the weights of the different factors i.e. $\mathrm{W}_{\mathrm{AS}}=0.209, \mathrm{~W}_{\mathrm{EA}}=0.118, \mathrm{~W}_{\mathrm{RA}}=0.099, \mathrm{~W}_{\mathrm{PO}}=0.077, \mathrm{~W}_{\mathrm{RP}}=0.162$, $\mathrm{W}_{\mathrm{TG}}=0.335$. Here tangible factor $(0.335)$ is conceived to be the most important factor followed by assurance (0.209); responsiveness (0.162); empathy (0.118); reliability (0.099) and professionalism (0.077).

As benchmarking is a continuous process, the AHP approach may provide easy methodology for benchmarking where criterion is considered in turn, a consensus choice of decision alternative is achieved. Though Benchmarking involves support from all departments, thus AHP can provide a common framework for different factors so that the same methodology is shared to maximize the efficiency and avoid inconsistency. The AHP methodology is very flexible that changing of relative weight is allowed at any time and new alternatives can be added as necessary. Different industries may involve their own goals and operational strategies, so the values of relative weights may be different. The use of AHP enables Industries to enter their own pair wise comparison to reflect their own management strategies so that the benchmarking outcome can provide a best solution meeting their existing and future business strategies.

\section{Benchmarking and Its Implementations}

In India there is extreme competition for car services as of same manufacturing industries hire different - 2 service provider thus there is close competition which causes for improvement at various levels. So the industries want to adopt benchmark model for achieving best in their field. Therefore, it is suggested that service industry should adopt a benchmarking approach to continuously assess and improve the performance. A benchmarking approach is a realistic approach for continuous improvements in quality and performance (Dattakumar \& Jagadeesh, 2003).Benchmarking in car services enables the company to constantly monitor and assess its performance for operating techniques against other best of class industries. The process is important to continuous improvement in an industry's service and expense levels, where some of benefits from benchmarking for Car Service industries include:

$>$ Improvement in market position of the service provider

$>$ Improvement in level of customer satisfaction

$>$ Identify information that will enhance throughput and lower expense

$>$ Improvement in information flow between all departments

$>$ Improvement in customer service and quality control

$>$ Reduced overall expenses

$>$ Improvement in team spirit and morale

Referring to the result of AHP, the goal is the selection of improvement alternative for Company A to considerate, the Tangibles values. To improve Tangibles, Company A had identified those good 
practices that can be learnt from the market leader (i.e. Competitor X) were changing their machines and equipment with building layout as per their interest. However, it indicates the evaluation standard of rating for the improvement in alternatives as per descending order in the demonstration only. Since different alternatives have their different evaluation standards, so there is requirement of defining their evaluations standard before selection of improved alternatives. By entering the ratings of sub-criteria for each changing opportunity into the step 3 of AHP methodology, the best practice can come out. Table no.4 shows the result of the selection of improved alternative with regard to each criteria and sub-criteria defined previously. Rearranging service capability with100 percent max is the best practice that Company A should implement to improve its on-time delivery and also to evaluate the improved alternatives from the market leader (Company X) so the best practice can be implemented. In fact, this is a continuous improvement process because the company can improve its weaknesses one by one. The flow chart of proposed benchmarking model for Indian Car Service Company “A” is shown below.

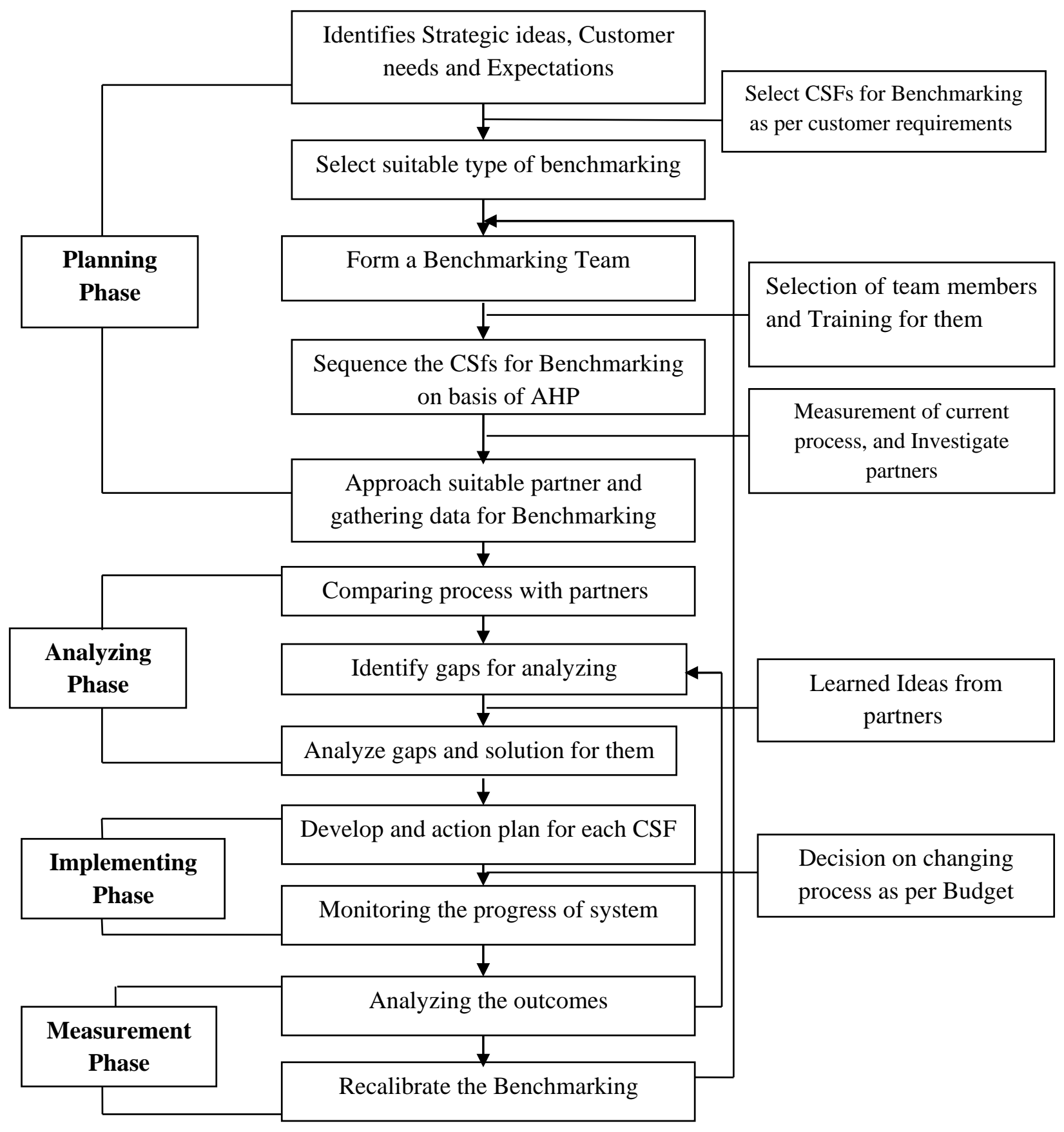

Fig. 4. Benchmarking model 
For adoption best practice, a benchmarking model shown in above figure no.4 is proposed for Indian car service company “A”, i.e. based on the literature outcome from Xerox benchmarking model (Camp, 1989) and 12-phase, 54-step benchmarking process (Annand \& Kodali, 2008). The proposed benchmarking model has four phases i.e. planning, analyzing, implementing and measurement that include 12 main steps as shown in figure no.4 which are discussed in brief.

The planning phase consists of five steps with addition of 3 sub steps which includes some necessary terms. Consequently, it may not be feasible to consider all CSFs at any one-time for benchmarking due to financial and non-financial constraints. The manufacturer and service provider should also consider the structural relationship of CSFs developed by AHP to decide which set of CSFs, be supposed to go for benchmarking in the first time and in subsequent turns for next step. A suitable type of benchmarking (i.e. internal, competitor, generic, process, functional, performance, strategic, competitive type, etc. (Singh \& Grover et al., 2014) should be adopted for the selected CSFs (i.e. fourth step). The benchmarking team should identify and collect the relevant information regarding potential benchmarking partners (i.e. fifth step) and this completes the planning phase. The analyzing phase comprises of three steps (sixth step), gap analysis (seventh step) and defining a set point for optimum gap reduction (eighth step)). The sixth step initiates with the identification of key performance indicators for each CSFs by the benchmarking team. The gap analysis for each selected CSFs should be carried out in the seventh step thus it may not be possible to bridge the entire gap in a single attempt. Therefore, a set point must be defined for optimum gap reduction by considering the constraints for a particular attempt. It will be fixed by the benchmarking team in the eighth step. This will concludes the analyzing phase. The implementing phase consists of two steps (i.e. ninth and tenth steps). The ninth step starts with developing and implementing an action plan for each CSFs where it must be monitored for proper execution and to know their progress on a real time basis (i.e. tenth step). The last phase is the measuring phase and it consists of two steps (i.e. 11th and 12th steps). The $11^{\text {th }}$ step starts with analyzing the outcomes and comparing with the corresponding targeted optimum reduction in the gaps fixed in the eighth step. The next attempt for optimum gap reduction is decided by the results of the above comparisons and existing internal and external environments for each selected CSFs. Finally, the benchmarking team should recalibrate the benchmark (i.e. 12th step). The proposed benchmarking approach is broad in nature and can be applied to different other industries once their structural framework of CSFs are find out.

\section{Conclusion}

Since achieving customer satisfaction is the main goal of service industries, so the derivation of the AHP should be done by customer's view, hence the benchmarking process can be customer-oriented. However, for the continuous improvement, selection of improvement action and the relative weights should be done by top management as they are decision makers. In this paper, CSFs are identified and classified into six categories in an Indian service context, with input from extensive literature reviews and discussions held with managers from feedback. An AHP methodology is proposed to develop the structural model and establish the relationships among the CSFs. In order to apply the AHP methodology, an Indian Service Car company "A" is considered. It is found that the "Tangibles" CSF has maximum dynamic power and minimum dependence level among the all CSFs. Therefore, the Tangibles follow by Assurance and Responsiveness should be designed taking the confidence of the management and customer at the beginning to create a win-win environment. A benchmarking model is developed on the basis of the structural model for CSFs which is a good instrument for enhancing the performance to feasible level in a short duration with minimum effort and resource. The findings of the proposed structural framework and benchmarking model for Indian automobile car Service Company "A" will serve as a guideline for successful adoption in the market. The proposed benchmarking model can be applied to different service or other environments capturing their unique environment which will reflect their own precedence considerations. 


\section{References}

Ahmed, A. M., Zairi, M., \& Alwabel, S. A. (2006). Global benchmarking for internet and e-commerce applications. Benchmarking: An International Journal, 13(1/2), 68-80.

Anand, G., \& Kodali, R. (2008). Benchmarking the benchmarking models. Benchmarking: An International Journal, 15(3), 257-291.

Baba, Deros, M., Mohd Yusof, S. R., Azhari, \& Salleh, M. (2006). A benchmarking implementation framework for automotive manufacturing SMEs. Benchmarking: An International Journal, 13(4), 396-430.

Baltacioglu, T., Ada, E., Kaplan, M. D., Yurt And, O., \& Cem Kaplan, Y. (2007). A new framework for service supply chains. The Service Industries Journal, 27(2), 105-124.

Boon-itt, S., \& Pongpanarat, C. (2011). Measuring service supply chain management processes: The application of the Q-sort technique. International Journal of Innovation, Management and Technology, 2(3), 217-221.

Brandmeier, R. A., \& Rupp, F. (2010). Benchmarking procurement functions: causes for superior performance. Benchmarking: An International Journal, 17(1), 5-26.

Büyüközkan, G., Feyzioğlu, O., \& Nebol, E. (2008). Selection of the strategic alliance partner in logistics value chain. International Journal of Production Economics, 113(1), 148-158.

Camp, R.C. (1989). Benchmarking: The search for industry best practices that lead to superior performance. ASQC Quality Press, Milwaukee, WI.

Cassell, C., Nadin, S., \& Older Gray, M. (2001). The use and effectiveness of benchmarking in SMEs. Benchmarking: An International Journal, 8(3), 212-222.

Chan, F. T., Chan, H. K., Lau, H. C., \& Ip, R. W. (2006). An AHP approach in benchmarking logistics performance of the postal industry. Benchmarking: An International Journal, 13(6), 636-661.

Chia, A., Goh, M., \& Hum, S. H. (2009). Performance measurement in supply chain entities: balanced scorecard perspective. Benchmarking: An International Journal, 16(5), 605-620.

Chin, K. S., Pun, K. F., Lau, C. S., \& Lau, H. (2001). Performance improvement of international roaming service-A benchmarking study. Benchmarking: An International Journal, 8(2), 120-131.

Choy, K. L., Chow, H. K., Lee, W. B., \& Chan, F. T. (2007). Development of performance measurement system in managing supplier relationship for maintenance logistics providers. Benchmarking: An International Journal, 14(3), 352-368.

Dattakumar, R., \& Jagadeesh, R. (2003). A review of literature on benchmarking. Benchmarking: An International Journal, 10(3), 176-209.

Dawkins, P., Feeny, S., \& Harris, M. N. (2007). Benchmarking firm performance. Benchmarking: An International Journal, 14(6), 693-710.

Dunn, S. C., \& Young, R. R. (2004). Supplier assistance within supplier development initiatives. Journal of Supply Chain Management, 40(2), 19-29.

Frei, F. X., \& Harker, P. T. (1999). Measuring aggregate process performance using AHP. European Journal of Operational Research, 116(2), 436-442.

Gangurde, S. R., \& Akarte, M. M. (2013). Customer preference oriented product design using AHPmodified TOPSIS approach. Benchmarking: An International Journal, 20(4), 549-564.

Gleich, R., Motwani, J., \& Wald, A. (2008). Process benchmarking: a new tool to improve the performance of overhead areas. Benchmarking: An International Journal, 15(3), 242-256.

Gomes, C. F., Yasin, M. M., \& Yasin, Y. (2010). Assessing operational effectiveness in healthcare organizations: a systematic approach. International Journal of Health Care Quality Assurance, 23(2), 127-140.

Hallgren, M., \& Olhager, J. (2009). Lean and agile manufacturing: external and internal drivers and performance outcomes. International Journal of Operations \& Production Management, 29(10), 976-999.

Hartley, J. L., \& Jones, G. E. (1997). Process oriented supplier development: building the capability for change. International Journal of Purchasing and Materials Management, 33(2), 24-29. 
Himes, A. H. (2007). Performance indicator importance in MPA management using a multi-criteria approach. Coastal Management, 35(5), 601-618.

Jackson, A. E., Safford, R. R., \& Swart, W. W. (1994). Roadmap to current benchmarking literature. Journal of Management in Engineering, 10(6), 60-67.

Jessica Hwang, L. J., \& Lockwood, A. (2006). Understanding the challenges of implementing best practices in hospitality and tourism SMEs. Benchmarking: An International Journal, 13(3), 337354.

Jones, K., \& Kaluarachchi, Y. (2008). Performance measurement and benchmarking of a major innovation programme. Benchmarking: An International Journal, 15(2), 124-136.

Kabir, G., Ahsan, M., \& Hasin, A. (2012). Framework for benchmarking online retailing performance using fuzzy AHP and TOPSIS method. International Journal of Industrial Engineering Computations, 3(4), 561-576.

Koller, M., \& Salzberger, T. (2009). Benchmarking in service marketing-a longitudinal analysis of the customer. Benchmarking: An International Journal, 16(3), 401-414.

Kourteli, L. (2000). Scanning the business environment: some conceptual issues. Benchmarking: An International Journal, 7(5), 406-413.

Leung, S. H., Chan, J. W., \& Lee, W. B. (2004). Benchmarking the role-modification process for successful knowledge transfer. Benchmarking: An International Journal, 11(6), 601-609.

Lin, M. C., Wang, C. C., Chen, M. S., \& Chang, C. A. (2008). Using AHP and TOPSIS approaches in customer-driven product design process. Computers in Industry, 59(1), 17-31.

Magd, H. A. (2008). Understanding benchmarking in Egyptian organizations: an empirical analysis. Benchmarking: An International Journal, 15(6), 742-764.

McAdam, R., Hazlett, S. A., \& Anderson-Gillespie, K. (2008). Developing a conceptual model of lead performance measurement and benchmarking: A multiple case analysis. International Journal of Operations \& Production Management, 28(12), 1153-1185.

Meybodi, M. Z. (2009). Benchmarking performance measures in traditional and just-in-time companies. Benchmarking: An International Journal, 16(1), 88-102.

Min, H., Min, H., \& Chung, K. (2002). Dynamic benchmarking of hotel service quality. Journal of Services Marketing, 16(4), 302-321.

Mitra Debnath, R., \& Shankar, R. (2008). Benchmarking telecommunication service in India: an application of data envelopment analysis. Benchmarking: An International Journal, 15(5), 584-598.

Moffett, S., Anderson-Gillespie, K., \& McAdam, R. (2008). Benchmarking and performance measurement: a statistical analysis. Benchmarking: An International Journal, 15(4), 368-381.

Mora Monge, C. A., Subba Rao, S., Gonzalez, M. E., \& Sohal, A. S. (2006). Performance measurement of AMT: a cross-regional study. Benchmarking: An International Journal, 13(1/2), 135-146.

Mukherjee, A., Nath, P., \& Nath Pal, M. (2002). Performance benchmarking and strategic homogeneity of Indian banks. International Journal of Bank Marketing, 20(3), 122-139.

Narasimhan, R., Swink, M., \& Kim, S. W. (2006). Disentangling leanness and agility: an empirical investigation. Journal of Operations Management, 24(5), 440-457.

Ojeda-Gomez, J., Simpson, M., Lenny Koh, S. C., \& Padmore, J. (2007). Achieving competitive advantage in the Mexican footwear industry. Benchmarking: An International Journal, 14(3), 289305.

Oliveira, P., \& Roth, A. V. (2012). Service orientation: the derivation of underlying constructs and measures. International Journal of Operations \& Production Management, 32(2), 156-190.

Parmar, D., Wu, T., Callarman, T., Fowler, J., \& Wolfe, P. (2010). A clustering algorithm for supplier base management. International Journal of Production Research, 48(13), 3803-3821.

Partovi, F. Y. (2001). An analytic model to quantify strategic service vision. International Journal of Service Industry Management, 12(5), 476-499.

Peng Wong, W., \& Yew Wong, K. (2008). A review on benchmarking of supply chain performance measures. Benchmarking: An International Journal, 15(1), 25-51.

Perçin, S. (2009). Evaluation of third-party logistics (3PL) providers by using a two-phase AHP and TOPSIS methodology. Benchmarking: An International Journal, 16(5), 588-604. 
Phuong Ta, H., \& Yin Har, K. (2000). A study of bank selection decisions in Singapore using the analytical hierarchy process. International Journal of Bank Marketing, 18(4), 170-180.

Rajagopala, S. V., Hughes, K. T., \& Uetz, P. (2009). Benchmarking yeast two-hybrid systems using the interactions of bacterial motility proteins. Proteomics, 9(23), 5296-5302.

Reza Mehregan, M., Dehghan Nayeri, M., \& Reza Ghezavati, V. (2010). An optimisational model of benchmarking. Benchmarking: An International Journal, 17(6), 876-888.

Richard, C. M., Tse, P., Ling, L., \& Fung, F. (2000). Enhancement of maintenance management through benchmarking. Journal of Quality in Maintenance Engineering, 6(4), 224-240.

Rickards, R. C. (2007). BSC and benchmark development for an e-commerce SME. Benchmarking: An International Journal, 14(2), 222-250.

Robson, A., \& Prabhu, V. B. (2001). What can we learn from "leading” service practitioners about business excellence?. Managing Service Quality: An International Journal, 11(4), 249-261.

Saaty, T. (2005). Theory and Applications of the Analytic Network Process. RWS Publications. Pittsburgh.

Saunders, M., Mann, R., \& Smith, R. (2007). Benchmarking strategy deployment practices. Benchmarking: An International Journal, 14(5), 609-623.

Simatupang, T. M., \& Sridharan, R. (2002). The collaborative supply chain. International Journal of Logistics Management, 13(1), 15-30.

Singh, B., Grover, S., \& Singh, V. (2015). A Benchmark model for internal assessment of industry using Fuzzy Topsis approach. International Journal of Recent advances in Mechanical Engineering (IJMECH), 4 (1), 93-105.

Singh, B., Grover, S., \& Singh, V. (2015). Application of Different Techniques used in Service Industries. AIMS International Conference, IIM Kozhikode.

Smith, A. M. (2000). Using consumer benchmarking criteria to improve service sector competitiveness. Benchmarking: An International Journal, 7(5), 373-388.

Sreekumar, S., and S. S. Mahapatra. (2011). Performance modeling of Indian business schools: a DEAneural network approach. Benchmarking: An International Journal, 18(2), 221-239.

Van Landeghem, R., \& Persoons, K. (2001). Benchmarking of logistical operations based on a causal model. International Journal of Operations \& Production Management, 21(1/2), 254-267.

Wainwright, D., Green, G., Mitchell, E., \& Yarrow, D. (2005). Towards a framework for benchmarking ICT practice, competence and performance in small firms. Performance Measurement and Metrics, 6(1), 39-52.

Wait, S., \& Nolte, E. (2005). Benchmarking health systems: trends, conceptual issues and future perspectives. Benchmarking: An International Journal, 12(5), 436-448.

Wynn-Williams, K. L. H. (2005). Performance assessment and benchmarking in the public sector: An example from New Zealand. Benchmarking: An International Journal, 12(5), 482-492.

Yasin, M. M. (2002). The theory and practice of benchmarking: then and now. Benchmarking: An International Journal, 9(3), 217-243.

Yasin, M. M. (2002). The theory and practice of benchmarking: then and now. Benchmarking: An International Journal, 9(3), 217-243.

Zairi, M., \& Youssef, M. A. (1995). Benchmarking critical factors for TQM: Part I: Theory and foundations. Benchmarking for Quality Management \& Technology, 2(1), 5-20. 